\title{
EFEITOS DE CONSEQUÊNCIAS CULTURAIS CONCORRENTES NA SELEÇÃO DE CULTURANTES
}

\section{EFFECTS OF CONCURRENT CULTURAL UPON CULTURANTS}

\author{
FÁBIO HENRIQUE BAIA \\ UNIVERSIDADE DE RIO VERDE, BRASIL \\ LAÉRCIA ABREU VASCONCELOS \\ UNIVERSIDADE DE BRASÍLIA, BRASIL
}

\begin{abstract}
RESUMO
Em uma metacontingência culturantes (compostos por contingências comportamentais entrelaçadas - CCEs - e seus produtos agregados - PA) são controlados por consequências culturais (CC). Este estudo investigou se a maximização de ganhos poderia exercer controle na seleção de culturantes em esquemas concorrentes. Participaram 24 universitários divididos em dois grupos. O Grupo 1 foi exposto a um delineamento AB e o Grupo 2 ao delineamento BA. A tarefa envolveu a escolha consensual de três participantes por um entre dois cartões. Na condição A, escolhas em azul produziam ganhos de $\mathrm{R} \$ 0,25$ e time out (TO) de 30s. Escolhas no cartão laranja geravam ganhos de R \$0,10 sem TO. Na condição B, escolhas em cartão amarelo produziam ganhos de R0,05 sem TO. Escolhas em vermelho geravam ganhos de R $\$ 0,10$ e TO de 180 s. Cada sessão durava 12 minutos. Ao fim da sessão, um participante era substituído. De modo geral, as gerações de ambos os grupos escolheram o cartão que produzia maiores ganhos ao fim da sessão. Os grupos também tenderam a manter a tradição de, no máximo, apenas uma escolha pelo cartão menos efetivo ao longo da sessão. Dados de verbalizações permitiram compreender de que modo ocorreu a transmissão de comportamento entre as gerações. Concluímos que os culturantes foram controlados pelas consequências que produziam maiores ganhos, mesmo quando tais consequências envolviam time out. Discutem-se as implicações dos resultados para a investigação de seleção de culturantes, além de questões de procedimento em investigações de metacontingências.
\end{abstract}

Palavras-Chave: metacontingência, culturantes, esquemas concorrentes, preferencia, universitários

\begin{abstract}
In a metacontingency, culturants (composed by interlocking behavioral contingencies - IBCs - plus aggregate product - PA) are controlled by cultural consequences. This study investigated whether a maximization of gains would determine the culturant's selections in concurrent schedules. Undergraduate students were divided into two groups. Group 1 was exposed to an $\mathrm{AB}$ design. Group two was exposed to a BA design. The task was a choice between two cards. In condition A, the choice of the blue card produced $\mathrm{R} \$ 0,25$ and a 30 -s time out (TO). Choice of the orange card produced $\mathrm{R} \$ 0,10$ and no TO. In condition $\mathrm{B}$, the choice of the yellow card produced $\mathrm{R} \$ 0,10$ and no TO. If participants chose the red card, they would obtain $\mathrm{R} \$ 0,05$ and a 180-sTO. Each session lasted $12 \mathrm{~min}$. At the end of the session, a participant was replaced. In general, all generations of both groups chose the card that produced larger gains at the end of session. The groups also tended to maintain the tradition of choosing the card that produced lower gains only once in the session. Data on verbalizations data suggested how to understand the transmission of behavior across generations. We concluded that culturants were controlled by consequences with larger gains, even if they involved the time out. We discuss implications of these results to the culturant's selection, as well as procedural issues in metacontingecies experiments.
\end{abstract}

Keywords: metacontingency, culturants, concurrent schedules, preference, undergraduate students.

Durante a execução do presente trabalho, Fábio era bolsista CNPq (Mestrado em Ciências do Comportamento), Departamento de Processos Psicológicos Básicos, Instituto de Psicologia, Universidade de Brasília. Correspondência sobre o presente trabalho deve ser enviada a Fábio Baia: Fazenda Fontes do Saber, Caixa Postal 104, CEP 75.901-970, Rio Verde, Goiás. fabio@unirv.edu.br 
A Análise do Comportamento investiga a cultura de dois modos. A primeira estabelece a cultura - o ambiente social - como variável independente. Desse modo, investiga-se como o ambiente social determina o comportamento de seus membros. A segunda lhe concede tratamento de variável dependente. Assim, investiga-se de que modo práticas culturais são mantidas ou alteradas em função de eventos ambientais (Andery, 2011). Nessa perspectiva, analistas do comportamento dedicam seus esforços para compreender processos e variáveis que são determinantes de fenômenos sociais.

Skinner (1953) chamou atenção para o fato de que boa parte do ambiente que determina o comportamento humano é constituído pelo comportamento de outros indivíduos. Em certas situações, o comportamento de um organismo só pode ser compreendido em função de sua relação com o comportamento de outrem. Quando um comportamento depende, ao menos parcialmente, da contingência tríplice do comportamento de outro organismo, diz-se que tais comportamentos estão envolvidos em contingências comportamentais entrelaçadas (CCEs) (Sampaio \& Andery, 2010).

Alguns estudos têm dedicado esforços para compreender de que modo as CCEs são mantidas por eventos ambientais. Uma possibilidade é a manutenção do entrelaçamento pelas consequências individuais produzidas por cada comportamento envolvido. Boren (1966) investigou a manutenção de um entrelaçamento por consequências individuais (reforços) liberadas por outro organismo. Duplas formadas por macacos, cada qual mantido em uma jaula experimental, tinham como tarefa pressionar 32 vezes uma alavanca para produzir alimento para seu parceiro. Assim, nenhum dos sujeitos poderia produzir consequências para seu próprio comportamento, pois estas eram mediadas pelo, ou dependiam do comportamento de outro organismo. Os sujeitos aprenderam a relação, isto é, pressionavam a alavanca. Entretanto, ao longo das sessões, os sujeitos diminuíram a frequência do responder, sem que nenhuma outra mudança ambiental tivesse ocorrido. Os autores consideraram que a utilização do método de operante livre pode ter propiciado dificuldades para manutenção do comportamento de ambos os sujeitos.

Outro fenômeno pelo qual CCEs podem ser mantidas é a produção agregada. O produto agregado (PA) é caracterizado por um efeito ambiental produzido exclusivamente pela resposta de duas ou mais pessoas. Assim, o PA não pode ser produzido pelo comportamento de apenas um indivíduo (Vichi \& Tourinho, 2011). Baum, Richerson, Efferson e Paciotti (2004) investigaram a manutenção e transmissão de uma prática cultural em uma situação que pode ser caracterizada por produção agregada. Participaram 278 universitários divididos em três grupos (TO $1 \mathrm{~min}$; TO $2 \mathrm{~min}$ e TO $3 \mathrm{~min}$ ) com diferentes gerações de quatro membros cada. A tarefa era a escolha consensual dos participantes por um de dois envelopes. Após a escolha, os participantes eram solicitados a resolver anagramas de cinco letras contidos nos envelopes. Findada a resolução de anagramas, os participantes recebiam individualmente ganhos em dinheiro - \$0,25 por escolhas do envelope azul e o cumprimento de um timeout (TO) - um período no qual novas escolhas não poderiam ser realizadas - de $1 \mathrm{~min}, 2$ min ou $3 \mathrm{~min}$, a depender do grupo. Os participantes também podiam receber $\$ 0,10$ por envelope vermelho. $\mathrm{O}$ TO foi programado apenas para escolhas do envelope azul. No trabalho de Baum et al. (2004), as consequências dependiam do entrelaçamento (escolha consensual) dos comportamentos dos participantes, assim tais consequências não poderiam ser produzidas fora do entrelaçamento.

As diferentes programações da relação entre ganhos financeiros e TO estabeleciam um dos dois envelopes como mais efetivo (isto é, o que gerava maiores ganhos ao longo da sessão). No Grupo TO $1 \mathrm{~min}$, o envelope azul foi o mais efetivo; para os grupos TO $2 \mathrm{~min}$ e TO $3 \mathrm{~min}$, o envelope vermelho era o mais efetivo. Cada sessão durava 12 min. Ao fim da sessão um participante deixava o experimento e um novo membro era inserido no grupo. A substituição de participantes permitia a constituição de novas gerações, o que possibilitou a observação da transmissão da tradição de escolhas entre gerações.

Os resultados encontrados por Baum et al. (2004) sugerem que as escolhas do grupo dependiam da magnitude dos ganhos financeiros associada ao tamanho do TO. O Grupo TO $1 \mathrm{~min}$ apresentou um padrão de escolhas que oscilava entre as gerações: algumas escolhiam preferencialmente (i.e., em mais de $50 \%$ das tentativas) o envelope azul, equanto outras gerações preferiram o envelope vermelho. Porém, de modo geral, foi constatada uma maior preferência pelo envelope azul para o Grupo TO $1 \mathrm{~min}$. O Grupo TO $2 \mathrm{~min}$ apresentou preferência pelo envelope vermelho. Porém, em três das 15 gerações houve preferência exclusiva (i.e., todas as escolhas realizadas por um único envelope) por azul. Por fim, o Grupo TO 3 min apresentou preferência exclusiva pelo envelope vermelho em quase todas as gerações. Quando não houve preferência exclusiva por vermelho, o Grupo TO $3 \mathrm{~min}$ apresentou preferência com índice acima de 0.6 pelo envelope vermelho.

Baum et al. (2004) também analisaram os tipos de regras proferidas pelos participantes. As regras foram categorizadas como instruções - que descreviam acuradamente as contingências; mitológicas - que descreviam inacuradamente as contingências; e coercitivas - que apenas especificavam o comportamento a ser emitido sem descrever contingências. Todos os três grupos emitiram instruções de modo similar. As regras mitológicas foram mais comuns nos grupos TO 2 min e TO 3 min. A coerção foi mais frequente no grupo TO 1 min. Em função dos resultados observados, os autores concluiram que as consequências e as regras emitidas foram suficientes para manter a tradição de escolhas, visto que as escolhas dependeram dos ganhos programados.

Outra maneira de compreender a manutenção de CCEs é por meio do conceito de metacontingências. Metacontingência descreve um procedimento no qual programa-se a relação de dependência entre contingências comportamentais entrelaçadas (CCEs), produto agregado 
(PA) e consequências culturais (CC) (Glenn \& Malott, 2004). Nessa relação, culturantes (formados por CCEs e o PA) são selecionados por consequências culturais (Hunter, 2012). As consequências culturais são funcionalmente distintas dos reforços (i.e., consequências individuais). As consequências individuais selecionam comportamentos operantes, enquanto as consequências culturais selecionam culturantes.

Vichi, Glenn e Andery (2009) investigaram se a programação de consequências culturais seria capaz de selecionar culturantes. Participaram oito universitários divididos em dois grupos. A tarefa utilizada exigia escolha consensual dos quatro participantes do grupo por uma linha de uma matriz. O experimentador escolhia uma das colunas de modo pré-determinado. Os participantes foram informados que a junção da escolha de linhas e colunas determinaria seus ganhos. Porém, os participantes recebiam o dobro do valor apostado em função do critério de distribuição de ganhos. Na condição A, o critério foi a distribuição igualitária entre os participantes. Na condição B, foi exigida a distribuição não-igualitária. Diferentemente de Baum et al. (2004), Vichi et al. (2009) não manipularam consequências individuais, mas sim consequências culturais, visto que o valor recebido era para o grupo e não para cada participante. Cabia ao grupo deliberar sobre a distribuição.

Desse modo, as CCEs eram os debates sobre como distribuir os ganhos. O PA foi caracterizado pelo tipo de distribuição dos ganhos entre participantes (se igual ou desigual). As consequências culturais eram os ganhos financeiros. Os resultados apontam que a distribuição de ganhos dependeu das exigências ambientais para a produção de novos ganhos. Assim, na condição A, foi observada distribuição igualitária e na condição B, distribuição não igualitária. Os autores concluíram que houve seleção de CCEs e PA em função das CC. Assim, a prática cultural de distribuir ganhos foi alterada sem intervenção no comportamento individual, mas apenas nas exigências ambientais para diferentes CCEs e PA.

Hunter (2012) também investigou se diferentes programações de contingências e metacontingências selecionaria diferentes padrões de CCEs, dado que nas contingências apenas consequências individuais (CI) estariam disponíveis, enquanto nas metacontingências $\mathrm{CI}$ e CC estariam disponíveis. Participaram quatro universitários distribuídos em duas duplas. A tarefa consistia em escolhas individuais por uma de três opções: (1) neutro - que gerava pontos para o participante sem relação com os pontos do parceiro; (2) partilhar - que adicionava pontos para ambos parceiros; e (3) roubar retirava pontos do parceiro e adicionava no contador de quem escolhia essa opção. Diferentes quantidades de pontos eram produzidas em função das escolhas. Havia duas condições: na condição Independente apenas as programações de pontos para as opções de escolhas estavam em vigor; na condição Interdependente, além da relação dos pontos nas opções partilhar e roubar, havia acréscimo de pontos no contador de ambos os participantes. Desse modo, em cada condição, diferentes
CCEs geravam maiores ganhos para ambos os participantes.

Os resultados de Hunter (2012) indicam que a seleção dos CCEs foi diferente quando CC estavam disponíveis (condição Interdependente) ou ausentes (condição Independente). Na condição Interdependente foi observada, como resultado, a seleção do culturante que produzia maximização de ganhos para ambos participantes; na condição Independente foi selecionado o entrelaçamento que produziu maximização de ganhos individuais. Assim, o autor conclui que houve seleção de culturantes por CC e seleção de CCEs por CI. O trabalho de Hunter (2012) é interessante pois aponta para uma situação na qual diferentes entrelaçamentos geravam consequências concorrentes. Porém, a concorrência foi entre ganhos gerados por $\mathrm{CI}$ versus $\mathrm{CI}$ e CC.

Diversos estudos têm sugerido a seleção de culturantes por consequências culturais (Baia, Azevedo, Segantini, Macedo, \& Vasconcelos, 2015; Caldas, 2009; Cavalcanti, Leite, \& Tourinho, 2014; Ortu, Becker, Woelz, \& Glenn, 2012). Até o momento nenhum trabalho avaliou diretamente uma situação de concorrência situação na qual duas ou mais consequências estão simultaneamente disponíveis, e a produção de uma das consequências impossibilita a produção das demais - entre CC na seleção de culturantes.

Este estudo teve como objetivo investigar a seleção de culturantes quando dois tipos de CC estavam disponíveis em situação concorrente, com diferentes relações de ganhos imediatos e TO. Na condição A, escolhas em azul geravam ganhos de $\mathrm{R} \$ 0,35$ e TO 30s, enquanto escolhas em amarelo produziam ganhos de $\mathrm{R} \$ 0,10$ sem $\mathrm{TO}$. Escolhas pelo cartão azul com maior magnitude de ganhos financeiros e TO produziam maiores ganhos imediatos e também maximização dos ganhos ao fim da sessão. Na condição B foram programados, para o cartão vermelho, ganhos de $\mathrm{R} \$ 0,05$ sem $\mathrm{TO}$; escolhas por amarelo geravam ganhos de $\mathrm{R} \$ 0,10$ e TO 180s. Nesta condição, escolhas pelo cartão com menor magnitude de ganhos e sem TO produziam menores ganhos imediatos, porém maximização de ganhos ao fim da sessão. Era esperado que os culturantes fossem sensíveis à magnitude de ganhos ao final da sessão, isto é, maximização dos ganhos. Assim, na condição A haveria maior índice de preferência para o cartão azul, enquanto na condição B o cartão amarelo teria maior preferência.

\section{MÉTODO}

\section{Participantes}

Participaram 24 universitários matriculados em cursos de Introdução à Psicologia sem experiência com conceitos de Psicologia Social ou contingências sociais. Os participantes foram distribuídos em dois grupos. Cada grupo era composto por 12 pessoas distribuídas em 10 gerações. Cada geração era formada por três membros. Após cada sessão, um membro era substituído por um novo participante. Todos os participantes assinaram o Termo de Consentimento Livre Esclarecido (TCLE) no qual constava a aprovação do Comitê de Ética em Pesquisa (Protocolo 059/2010). 


\section{Material e Ambiente}

Foram utilizados lápis, caneta, folha de registro, 600 folhas de papel revista medindo $16 \mathrm{~cm}$ de altura por $20 \mathrm{~cm}$ de largura, quatro cartões de papel nas cores azul, laranja, amarelo e vermelho, três cronômetros, uma filmadora, quatro copos de plásticos e 70 reais divididos em moedas de $\mathrm{R} \$ 0,05, \mathrm{R} \$ 0,10$ e $\mathrm{R} \$ 0,25$ centavos. A pesquisa foi realizada no Laboratório de Análise Experimental do Comportamento com uma mesa e cinco cadeiras.

\section{Sessões e Delineamento}

Neste estudo, uma sessão era encerrada após 30 min. A sessão foi dividia em duas partes de $15 \mathrm{~min}$. Em cada parte vigorava uma condição. Ao fim da sessão era realizada a Fase de Distribuição de Ganhos, na qual os participantes decidiam, sem a interferência do experimentador, de que modo distribuir os ganhos obtidos durante a sessão. Após a distribuição de ganhos, era realizada a Fase de Substituição de Participantes. Nesta fase, o participante com maior história com a tarefa (i.e., tempo de participação) deixava o experimento e um novo participante era inserido na situação experimental. Assim, a Fase Substituição permitia a constituição de uma nova geração. Durante as duas primeiras gerações, mais de um participante tinha a mesma história com a tarefa, portanto, o critério utilizado foi a proximidade do participante à filmadora. Os participantes com mais proximidade foram os primeiros a deixar a tarefa.

Havia dois grupos neste estudo. As gerações do Grupo 1 foram expostas primeiramente à condição $\mathrm{A} \mathrm{e}$, posteriormente, à condição $\mathrm{B}$. As gerações do Grupo 2 foram expostas primeiro à condição $\mathrm{B}$ e, posteriormente, à condição A. O objetivo dessa manipulação foi testar possíveis efeitos de ordem.

\section{Procedimento}

Os participantes foram expostos a uma tarefa na qual era exigida uma escolha consensual por um entre dois cartões. A Tabela 1 apresenta as fases realizadas neste estudo. A primeira geração de cada grupo foi exposta a um Pré-Treino. Durante o pré-treino, eram lidas instruções gerais que informavam aos participantes a exigência de realizarem escolhas consensuais e que, na ausência de consenso, o experimentador aguardaria até que todos os três membros da geração concordassem com a escolha por um cartão. As instruções também mencionavam a exigência de confecção de aviões de papel com um único modelo padrão, e que os ganhos obtidos durante a sessão seriam distribuídos pelos próprios participantes ao fim da sessão. Os participantes não eram informados sobre a duração da sessão ou do tempo que cada condição permaneceria em vigor. A distribuição de ganhos era realizada pelos participantes sem que houvesse interferências do pesquisador. Por fim, as instruções gerais mencionavam que ao fim de cada sessão, um participante deixaria o experimento e um novo membro seria inserido.

O Pré-treino também foi utilizado para ensino do modelo padrão de avião de papel a ser produzido por todos os participantes durante o experimento. A determinação de

um modelo específico de avião foi realizada para diminuir a variabilidade de tempo gasto na produção de aviões entre gerações. Para ensino do modelo, foi utilizado o processo de modelação. $\mathrm{O}$ experimentador entregava uma folha de papel para cada participante e solicitava que imitassem cada passo por ele demonstrado. Para confecção do modelo, eram necessárias seis dobraduras no papel. O experimentador realizava a primeira dobradura $\mathrm{e}$ aguardava que todos os participantes imitassem tal comportamento. A seguir era realizada a segunda dobradura e, novamente, aguardava-se até que todos os participantes houvessem terminado. Esse processo foi realizado até que as seis dobraduras fossem realizadas. Ao final da primeira modelação, o experimentador perguntava se todos se sentiam capazes de confeccionar o avião idêntico ao modelo. Caso a resposta fosse negativa, era repetida a modelação. Se todos participantes respondessem positivamente, o experimentador entregava uma nova folha de papel e solicitava que novos aviões fossem confeccionados sem a ajuda do experimentador. Se algum participante não conseguisse confeccionar o avião conforme modelo, o experimentador repetia a modelação para todos os participantes. Se todos os aviões confeccionados correspondessem identicamente ao modelo, era iniciada a tarefa geral. Esta fase era realizada somente no início da geração 1 (G1) de cada grupo. O tempo utilizado nesta fase não foi contabilizado no tempo de sessão.

Tabela 1

Descrição dos Eventos em Cada Fase do Estudo.

Fases Descrição dos eventos

Pré-treino

Leitura das instruções gerais e modelação da confecção de aviões

Descrição de um
ciclo

Distribuição dos Ganhos

Substituição de Participantes
Escolhas de cartões

Tarefas distratoras

Apresentação das consequências

Participantes distribuíam os ganhos obtidos na sessão sem interferência do experimentador
O participante com maior história com a tarefa deixava o experimento e era substituído por um participante ingênuo.

Nota: Os participantes da primeira geração foram substituídos pela proximidade com a filmadora, dado que todos tinham a mesma história com a tarefa.

No inicio de cada ciclo, o experimentador apresentava dois cartões e solicitava que os participantes realizassem a escolha consensual (i.e., todos os três membros verbalizarem oralmente que concordavam com a escolha) de um cartão. Em cada condição, havia dois cartões de diferentes cores sendo, azul e laranja na condição A e amarelo e vermelho na condição B. As 
contingências comportamentais entrelaçadas envolviam o debate verbal dos três participantes que compunham o grupo para deliberação da escolha de um cartão. $\mathrm{O}$ anuncio da escolha consensual por um dos cartões caracterizava o produto agregado. Afim de garantir a consensualidade da escolha por um cartão, após algum participante anunciar a escolha por um dos cartões, o pesquisador perguntava se todos concordavam. Caso um dos participantes afirmasse que não concordava com a escolha do grupo, o pesquisador aguardava o fim do debate caracterizado por um novo anuncio de escolha consensual. As escolhas sempre deveriam ser consensuais, por isso escolhas não consensuais não foram registradas.

Um ciclo consistia da escolha de um dentre dois cartões, realização de uma tarefa distratora e consequências programadas para as escolhas.

Escolha de um dos cartões - Dois cartões de cores distintas eram dispostos sobre a mesa, lado a lado, e os participantes deveriam escolher um, consensualmente. Após a escolha consensual, os participantes produziam quatro aviões de papel.

Tarefa distratora - A tarefa distratora era a confecção de aviões de papel. No trabalho de Baum et al. (2005) foram utilizados anagramas como tarefas distratoras, porém em um estudo piloto foi observado que os anagramas eram resolvidos em diferentes quantidades de tempo. Assim, foi decido utilizar a construção de aviões de papel, já que o tempo de execução era similar durante a realização do estudo piloto. O objetivo dessa tarefa distratora era evocar o debate, além de dificultar a descrição verbal das manipulações programadas neste estudo. Após a confecção dos aviões, as consequências das escolhas eram liberadas.

Liberação das consequências programadas - As consequências foram caracterizadas por moedas depositadas em um recipiente e quando fosse o caso, um timeout (TO) um período de espera no qual novas escolhas não poderiam ser realizadas. Ao fim da liberação das consequências programadas, um novo ciclo se iniciava. A Tabela 2 apresenta as programações adotadas nas condições A e B. $\mathrm{Na}$ condição $\mathrm{A}$, escolha por cartão azul produzia como consequências R\$0,25 e TO de 30s. Escolhas em laranja produziam ganhos de $\mathrm{R} \$ 0,10$ e nenhum TO. Na condição B, escolhas por cartão vermelho produziam $\mathrm{R} \$ 0,10$ e TO de 180s. Escolhas por cartão amarelo tinham como consequências depósito de moedas no valor de $\mathrm{R} \$ 0,05$ e nenhum TO.

Tabela 2

Programação de Eventos para Cada Cartão em Cada Condição. Condições Cartão

\begin{tabular}{lll} 
Condição A & Azul & Laranja \\
Tarefa de distração & 4 aviões & 4 aviões \\
Ganhos & $\mathrm{R} \$ 0,25$ & $\mathrm{R} \$ 0,10$ \\
Timeout & $30 \mathrm{~s}$ & - \\
& & \\
Condição B & Amarelo & Vermelho \\
Tarefa de distração & 4 aviões & 4 aviões \\
Ganhos & $\mathrm{R} \$ 0,05$ & $\mathrm{R} \$ 0,10$ \\
Timeout & - & $180 \mathrm{~s}$ \\
\hline
\end{tabular}

As programações de consequências estabeleciam que escolhas em azul (condição A) e escolhas em amarelo (condição B) produziam maiores ganhos ao fim da sessão, isto é, de magnitude maior. As duas condições foram programadas de modo que na condição $\mathrm{A}$, maiores ganhos eram produzidos na alternativa com $\mathrm{TO}$, ao passo que na condição B, a alternativa com ausência de TO era mais vantajosa. Essa manipulação teve como objetivo evitar que as escolhas dos participantes fossem determinadas por evitar o período de TO e não pelos ganhos financeiros programados.

\section{Procedimento de Análise dos Resultados}

As escolhas consensuais dos participantes foram registradas e apresentadas como preferência por um cartão. A preferência foi calculada por meio da divisão da quantidade de escolhas consensuais (produto agregado) por cartão mais efetivo pelo total de escolhas realizadas durante a geração. Deste modo, os valores poderiam variar de 0 (preferência exclusiva por cartão menos efetivo) a 1.0 (preferência exclusiva por cartão mais efetivo). Valores acima de 0.5 foram considerados como acima da linha do acaso. Isto é, as escolhas estavam sob controle das consequências programadas.

Os registros em vídeo também foram analisados em termos de topografias de comportamentos verbais e não verbais. $\mathrm{O}$ procedimento de análise envolveu transcrever as respostas verbais dos participantes, além de descrever a topografia dos comportamentos não verbais. Um experimentador e um observador independentes assistiram separadamente as gravações em vídeo de todas as gerações de ambos os grupos e registraram as verbalizações que se referiam às contingências progamadas. As verbalizações foram categorizadas como: 1) instrução acurada: verbalizações que descrevem corretamente, parcialmente ou completamente, as contingências experimentais; 2) instrução inacurada: descrições incorretas de contingências experimentais; 3) instrução coercitivas: verbalizações do tipo mando em que os membros não descreviam contingência(s) em vigor (e.g., "apenas escolha azul"). Após os dois observadores terem realizado o registro em categorias, foi obitdo o índice de $90 \%$ de acordo entre observadores. O cálculo para o índice de acordo foi total de acordos dividido pelo total de acordos mais total de desacordos, multiplicado por 100 .

Para representar a utilização da estratégia acima citada foi utilizado o critério de tradição cumulativa similar ao critério de tradição liberal proposto por Baum e et al. (2004). O critério de tradição cumulativa foi construído atribuindo um ponto para cada geração que apresentasse no máximo uma escolha no cartão menos efetivo. Quando houve mais de uma escolha do cartão menos efetivo, o valor atribuído à geração anterior foi repetido.

\section{RESULTADOS}

A Figura 1 apresenta a preferência por cartão mais efetivo (isto é, o cartão cuja escolha geraria maior magnitude dos ganhos financeiros ao longo da sessão) ao 
longo das gerações dos dois grupos. Como é possível observar na figura, de modo geral as gerações apresentaram maior preferência pelo cartão mais efetivo valores acima de 0.5 . Na condição $\mathrm{A}$, as gerações 1 e 2 do Grupo 1 apresentaram o menor índice de preferências por cartão mais efetivo naquele grupo. Da terceira à décima geração, os participantes apresentaram preferência pelo cartão azul com índices superiores a 0.9 . Na condição B, todas as 10 gerações do Grupo 1 apresentaram índices de preferência por cartão amarelo (mais efetivo) acima de 0.8 .

As sete primeiras gerações do Grupo 2 apresentaram índice de preferência acima de 0.7. Durante a geração 8 , a preferência por cartão azul caiu para 0.1 , assim, a preferência por cartão laranja (cartão menos efetivo) foi de 0.9 . O índice de preferência da geração 8 se repetiu na geração 9. Ao concluírem a participação no experimento, cada membro dos Grupos 1 e 2 foi solicitado a explicar os critérios individuais que utilizaram para realizar suas escolhas. A seguir serão apresentadas algumas descrições dos participantes P28, P29 e P30 que compuseram a oitava geração do Grupo 2. As verbalizações dos demais participantes de ambos os grupos não serão apresentadas, uma vez que as descrições destes membros apenas confirmavam o controle pelas consequências culturais. Entretanto, as descrições dos participantes da geração 8 e 9 do Grupo 2 auxiliam na compreensão da alteração da preferência durante a condição A para estas gerações.
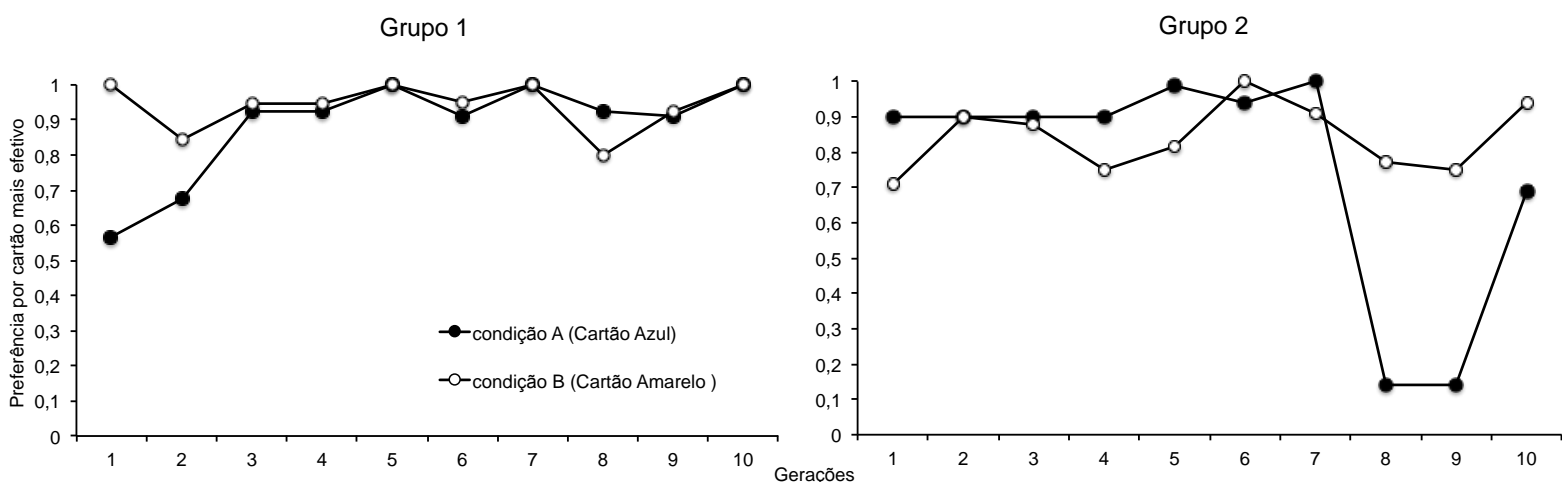

Figura 1. Preferência por cartão mais efetivo ao longo das gerações. No painel à esquerda são apresentados os dados referentes ao Grupo 1. No painel da direita, os dados referentes ao Grupo 2. Círculos pretos indicam preferência pelo cartão azul na condição A. Círculos brancos indicam preferência pelo cartão amarelo na condição B.

O participante P28 apresentou justificativas para suas escolhas do cartão laranja na condição A, referindose aos comportamentos de seus parceiros P29 e P30. O participante sentiu-se incomodado com P29, o qual the pareceria indicar desinteresse pela situação experimental. Um experimentador analisou os vídeos com a participação de P29 no experimento (gerações 7, 8 e 9). Foi observado que seus comportamentos possibilitavam a interpretação de P28. Entre as topografias dos comportamentos de P29 estavam: olhar para o lado evitando contato com os demais membros, bocejar, permanecer calado e anunciar suas escolhas apenas após a manifestação dos outros membros, e ainda, risadas e balanço da cabeça em sinal negativo durante a etapa de consequências culturais. P28 relatou também que a entrada de P30 que falava rapidamente e dedilhava sobre a mesa o influenciou a escolher o cartão laranja. Portanto, na interpretação de P28, a inexistência de TO evitava interações verbais entre os membros do grupo, o que lhe parecia satisfazer P29, além de evitar o dedilhar na mesa de P30 que permaneceria envolvido com a confecção dos aviões.

$\mathrm{Na}$ entrevista pós-participação, P29 relatou não ter interesse pelo dinheiro que era entregue como parte da consequência cultural, devido à pequena quantia estabelecida, sendo sua participação controlada apenas pela obtenção de créditos no curso de Introdução à Psicologia. Quanto às escolhas do cartão laranja, P29 relatou que estas permitiam o engajamento em comportamentos não-sociais como a produção de aviões, evitando interação com os demais membros até que o tempo de participação se esgotasse. Novamente, a análise dos vídeos é consistente com as verbalizações de P29. Foi observado que P29 foi o membro da geração a confeccionar o maior número de aviões de papel por ciclo. Por fim, P30 relatou que escolhia o cartão laranja para evitar conflitos entre P28 e P29. Após a saída de P29 (geração 10), a escolha efetiva tornou-se preferida com índice próximo de 0.7. Durante a condição $\mathrm{A}$, todas as gerações do Grupo 2 apresentaram preferência por cartão azul com índices superior a 0.7 .

Outra maneira de observar a tradição de escolhas entre gerações é comparar em termos absolutos as escolhas de uma geração com a geração anterior, pois a preferência pode variar em função da quantidade de ciclos ocorridos durante uma geração. Ainda que duas gerações consecutivas tenham realizado apenas uma escolha do cartão não efetivo, o valor de preferências poderá ser diferente. Por exemplo, na condição A, o Grupo 1, geração 8 apresentou uma escolha por cartão laranja e 12 escolhas por azul, resultando em preferência de 0.76 por azul. Por outro lado, a geração 9 apresentou uma escolha por laranja e 10 escolhas por azul, resultando na preferência de 0.90 por azul. A necessidade dessa análise ocorre em função de uma estratégia adotada por quase todas as gerações de 
ambos os grupos. Tal estratégia consistia, sistematicamente, em pelo menos uma escolha do cartão menos efetivo. Assim, os membros mais antigos emitiam uma escolha no cartão não efetivo para que o novo membro da geração pudesse entrar em contato com as consequências culturais programadas para cada cartão.

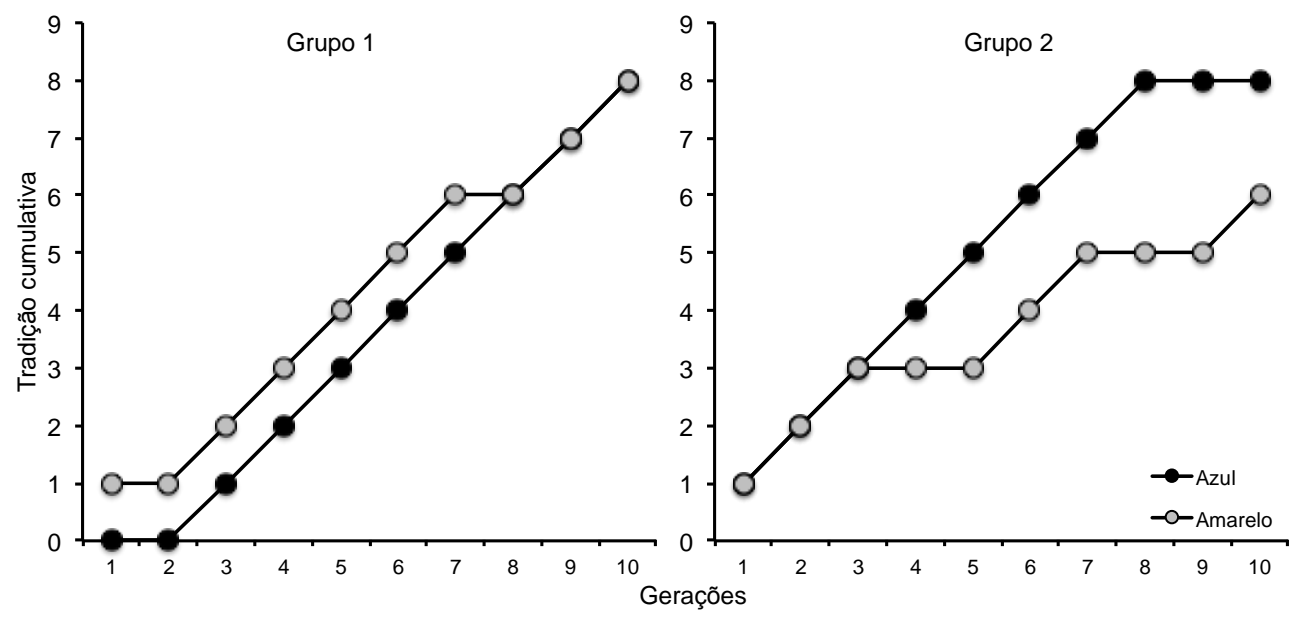

Figura 2. Tradição cumulativa dos Grupo 1 e 2 ao longo das gerações. O painel da esquerda apresenta os dados do Grupo 1 . O painel da direita apresenta os dados do Grupo 2. Círculos pretos representam tradição de escolhas por cartão azul na condição A. Círculos cinza representam tradição de escolhas por cartão amarelo na condição B.

A Figura 2 apresenta o registro cumulativo da utilização da estratégia de escolha única no cartão menos efetivo. A repetição do uso desta estratégia revela uma tradição ao longo das gerações. Na Figura 2, quando há inclinação na curva, isto representa utilização da estratégia que atendeu o critério de tradição cumulativa. Por outro lado, quando a curva mantém-se paralela ao eixo das abscissas (gerações), isso reflete que o grupo realizou mais de uma escolha do cartão menos efetivo, ou seja, houve abandono da estratégia de demonstração das contingências programadas para cada cartão.

Os dados obtidos mostram que no Grupo 1, durante a condição $\mathrm{A}$, apenas as duas primeiras gerações não atendaram ao critério de tradição cumulativa para o cartão azul. As oito gerações seguintes utilizaram a estratégia de escolher, no máximo, uma vez o cartão laranja. Na condição B, apenas duas gerações (geração 2 e geração 7) não atenderam ao critério de tradição cumulativa. No Grupo 2, na condição B (primeira a ser exposta ao Grupo 2), seis das 10 gerações atenderam ao critério de tradição cumulativa. As gerações 3, 4, 7 e 8 realizaram mais de uma escolha pelo cartão não efetivo. $\mathrm{Na}$ condição $\mathrm{A}$, apenas as três últimas gerações não atenderam ao critério de tradição cumulativa pelo cartão azul.

Os resultados da divisão dos ganhos foram registrados - todas as gerações de ambos os grupos dividiram o montante acumulado igualmente entre os membros quando a quantia obtida era passível de divisão exata por três. Quando a quantia não permitia a divisão exata, o membro mais antigo recebia o maior valor. Ocorreram apenas duas exceções no padrão de divisão, ambas, respectivamente, nas gerações 8 e 9 do Grupo 1 . O participante P10 renunciou a seus ganhos na geração 8 e não aceitou que o participante $\mathrm{P} 9$ recebesse maior valor durante a divisão dos ganhos acumulados da geração 9 . Nesse caso, P8 recebeu a quantia superior.

Para compreender como ocorreu a transmissão de comportamentos operantes que compunham os culturantes, foi realizada análise do comportamento verbal dos participantes, em especial as verbalizações que se referiam às contingências programadas na tarefa geral (composta pelas etapas de escolha consensual, tarefa de distração, consequências, divisão dos ganhos e substituição de membros). Essas verbalizações tiveram uma função comum: instruir os membros a escolher um dos cartões em função das contingências programadas. As verbalizações poderiam ser feitas tanto para os membros antigos como para os novos membros, portanto, a análise aqui desenvolvida não diferenciou a quem se dirigia a instrução - se o ouvinte era um membro antigo ou um novo membro - já que a função era a mesma.

A Tabela 3 apresenta os resultados da categorização das verbalizações para o Grupo 1 e a Tabela 4 apresenta os resultados do Grupo 2. De modo geral, houve sistematicidade nos dados. Análise intra-grupo revela que para ambos: 1) as verbalizações inacuradas diminuíram ao longo das gerações; 2) as verbalizações acuradas e coercitivas oscilaram sem que se possa afirmar com segurança que houve qualquer tendência. A comparação entre grupos revela que os participantes do Grupo 2 emitiram menos verbalizações do que o Grupo 1. Um dado não apresentado nas Tabelas 3 e 4, mas de certa importância, refere-se ao momento em que ocorreram as verbalizações coercitivas. Em todos as gerações em que houve a ocorrência de verbalizações coercitivas, elas sempre ocorreram apenas no ínicio da sessão. 
Tabela 3

Categorização das Verbalizações do Grupo 1

\begin{tabular}{|c|c|c|c|c|c|c|c|}
\hline \multirow[t]{2}{*}{ Geração } & \multicolumn{4}{|c|}{ Valores Absolutos } & \multicolumn{3}{|c|}{ Valores Proporcionais } \\
\hline & Acuradas & Inacuradas & Coercitivas & Total & $\begin{array}{c}\text { Acuradas } \\
(\%)\end{array}$ & $\begin{array}{c}\text { Inacuradas } \\
(\%)\end{array}$ & $\begin{array}{c}\text { Coercitivas } \\
(\%)\end{array}$ \\
\hline 1 & 21 & 14 & 0 & 35 & 60,0 & 40,0 & - \\
\hline 2 & 17 & 9 & 0 & 26 & 65,3 & 34,7 & - \\
\hline 3 & 15 & 10 & 3 & 28 & 53,6 & 35,7 & 10,7 \\
\hline 4 & 21 & 3 & 2 & 26 & 80,7 & 10,7 & 9,3 \\
\hline 5 & 9 & - & 1 & 10 & 90,0 & - & 10 \\
\hline 6 & 7 & - & 4 & 11 & 63,6 & - & 36,4 \\
\hline 7 & 9 & - & - & 9 & 100,0 & - & - \\
\hline 8 & 19 & 2 & 1 & 22 & 86,3 & 9,1 & 4,6 \\
\hline 9 & 7 & 3 & 2 & 12 & 58,3 & 25 & 16,7 \\
\hline 10 & 8 & 2 & 2 & 12 & 66,6 & 16,7 & 16,7 \\
\hline
\end{tabular}

Tabela 4

Categorização das Verbalizações do Grupo 2.

\begin{tabular}{|c|c|c|c|c|c|c|c|}
\hline \multirow[t]{2}{*}{ Geração } & \multicolumn{4}{|c|}{ Valores Absolutos } & \multicolumn{3}{|c|}{ Valores Proporcionais } \\
\hline & Acuradas & Inacuradas & Coercitivas & Total & $\begin{array}{c}\text { Acuradas } \\
(\%)\end{array}$ & $\begin{array}{c}\text { Inacuradas } \\
(\%)\end{array}$ & $\begin{array}{c}\text { Coercitivas } \\
(\%)\end{array}$ \\
\hline 1 & 23 & 5 & 1 & 29 & 80,6 & 17,2 & 3,4 \\
\hline 2 & 9 & 1 & 0 & 10 & 90,0 & 10 & - \\
\hline 3 & 6 & - & - & 6 & 100,0 & - & - \\
\hline 4 & 5 & 1 & 0 & 6 & 83,3 & 17,7 & - \\
\hline 5 & 2 & 5 & 1 & 8 & 25,0 & 62,5 & 12,5 \\
\hline 6 & 11 & 4 & 9 & 24 & 45,8 & 16,6 & 37,6 \\
\hline 7 & 4 & - & 2 & 6 & 66,6 & - & 33,4 \\
\hline 8 & 3 & - & - & 3 & 100,0 & - & - \\
\hline 9 & 1 & - & - & 1 & 100,0 & - & - \\
\hline 10 & 5 & 1 & - & 12 & 83,4 & 17,6 & - \\
\hline
\end{tabular}

\section{DISCUSSÃO}

Neste estudo foi observado que, de modo geral, os culturantes ficaram sob controle da maximização de ganhos ao final da sessão. Como pode ser observado na Figura 1, de modo geral, houve maior preferência pelo cartão mais efetivo. Isto é, os participantes tendiam a escolher, consensualmente, o cartão relacionado a maiores ganhos ao fim da sessão. Hunter (2012) também observou na condição interdependente que os culturantes selecionados eram aqueles que produziam maiores ganhos para ambos os participantes. Estes resultados sugerem que culturantes ficam sob controle de consequências culturais com maiores magnitudes de ganhos ao longo da sessão. Apenas na condição A do Grupo 2, geração 8 e 9, ocorreu preferência pelo cartão menos efetivo. Não se pode afirmar que naquelas gerações (8 e 9, Grupo 2) a preferência foi determinada pela ausência de TO. Porém, os relatos verbais pós-sessão e as imagens sugerem que variáveis individuais tiveram peso maior na determinação das escolhas. Vichi et al. (2009) também encontraram resultados nos quais em alguns ciclos as consequências culturais não foram capazes de selecionar os culturantes.
Naquele estudo, os participantes tendiam a distribuir igualitariamente os ganhos obtidos, mesmo na condição na qual ganhos desiguais eram exigidos para produção de CCs.

Vichi et al. (2009) precisaram intervir na distribuição de ganhos. Os experimentadores informavam que parte dos ganhos obtidos seriam retidos para um "banco"; desse modo, o valor a ser distribuído impedia a divisão igualitária. Somente após essa intervenção é que os participantes atenderam ao critério de estabilidade para mudança de condição. No presente estudo, não foi necessário qualquer tipo de intervenção por parte dos experimentadores. A saída de P29 foi suficiente para que os culturantes com escolha por cartão azul voltassem a um índice de preferência próximo a 0.7 . De todo modo, esses resultados sugerem que outros eventos ambientais (como o dedilhar na mesa de P29) não programados pelos experimentadores podem ter interferido no controle de culturantes pelas consequências culturais programadas. Tanto Vichi et al. quanto o presente estudo não manipularam reforços (consequências individuais) para os comportamentos operantes envolvidos no entrelaçamento. 
É possível que a ausência da programação de reforços tenha permitido que outros eventos ambientais interferissem na seleção de culturantes. De todo modo, como mencionado anteriormente, o efeito dessas possíveis variáveis estranhas não se manteve após a saída de P29.

Os resultados da Figura 2 apresentam a tradição cumulativa entre gerações. Como pode ser observado na figura, o Grupo 1 na condição A passou a escolher o cartão azul tradicionalmente após a geração 3. $\mathrm{Na}$ condição B, uma vez estabelecida a escolha por cartão amarelo (geração 3), apenas a geração 8 não continuou a perpetuar a prática de escolher, no máximo, uma vez o cartão vermelho. No Grupo 2, condição B (primeira condição a qual o grupo foi exposto), quatro das 10 gerações não perpetuaram a tradição. $\mathrm{Na}$ condição $\mathrm{A}$ a tradição foi perpetuada em sete das 10 gerações consecutivamente. Esses resultados sugerem que a condição A tinha programações mais efetivas no controle dos culturantes quando comparada à condição $B$. Entretanto, esse resultado diverge dos achados de Baum et al. A condição A do presente estudo possuiu similaridade de programações com o Grupo TO 1 min de Baum et al. (2004). Naquele estudo, no Grupo TO 1, escolhas em azul geravam ganhos de 0,25 centavos de dólar e a magnitude do time out era similar ao tempo gasto para a realização da tarefa de distração. Escolhas no cartão vermelho produziam ganhos de 0,10 centavos de dólar e nenhum TO. Já a condição B do presente estudo difere apenas na magnitude dos ganhos para o cartão mais efetivo $(0,05$ centavos para o presente estudo e 0,10 centavos de dólar em Baum et. al., 2004) se comparado às programações para o Grupo TO 3 min de Baum et al. Enquanto Baum et. al. (2004) encontraram maior tradição de escolhas entre gerações para o Grupo TO 3 min, nós encontramos maior tradição na condição A. Não está claro quais variáveis poderiam ter determinado a diferença, entre os resultados encontrados neste estudo, daqueles obtidos por Baum et al.

Os resultados de tradição de escolhas podem ser compreendidos como uma demonstração de linhagens culturais. Glenn (2004) define linhagens culturais como a recorrência de CCEs e seus produtos. Dito de outra forma, linhagens culturais referem-se à repetição de culturantes entre diferentes gerações de indivíduos. Nesse sentido, os resultados observados na Figura 2 podem ser compreendidos como demonstração de linhagens culturais. No caso deste estudo, é possível sugerir que as linhagens culturais ocorreram em função das diferenças entre as consequências culturais programadas. Consequências que produziam maiores ganhos selecionaram a linhagem cultural de escolha por cartão mais efetivo. Outro resultado do presente estudo relacionado à linhagem cultural foi a categorização das verbalizações.

A transmissão de culturantes entre gerações dependeu, ao menos parcialmente, das verbalizações proferidas por membros antigos aos novos participantes no início das sessões. As Tabelas 3 e 4 sumarizam os resultados das instruções proferidas pelos participantes. Em ambos os grupos, as instruções acuradas foram mais frequentes do que instruções inacuradas ou coercitivas. Baum et al. (2009) encontraram resultados similares em relação ao tipo de verbalização. Glenn (1989) destaca que o comportamento verbal tem importante papel na transmissão de práticas culturais. Segundo a autora, o comportamento verbal atua como contingência de suporte para o comportamento não verbal. Este foi o caso da estratégia de escolha única em cartão menos efetivo. Os participantes antigos tendiam a descrever acuradamente as contingências programadas para cada cartão. Depois realizavam uma escolha em cada cartão. Essa estratégia instruía os novos membros, além de propiciar o contato com as contingências e metacontingências em vigor.

Este estudo contribui para literatura ao demonstrar que a seleção de culturantes pode ser afetada pela maximização de ganhos. Foram programadas duas metacontingências em esquemas concorrentes. Os culturantes que ocorreram com maior frequência foram aqueles que produziram consequências que geravam maiores ganhos ao fim da sessão. A programação de situações concorrentes tem maior similaridade com o ambiente natural do que situações nas quais apenas um único culturante está relacionado à produção de consequências. Práticas culturais como o uso da água envolvem diversas possibilidades de culturantes que, por sua vez, produzirão diferentes consequências.

Herrstein (1961) formulou a lei da igualação cuja previsão é a de que em esquemas concorrentes o responder operante é proporcional aos reforços obtidos em cada elo. Os resultados encontrados no presente estudo não podem ser interpretados segundo a lei da igualação, dado que foi utilizado um procedimento de tentativas discretas. Assim, cada culturante estava diretamente relacionado à disponibilização de uma consequência. Estudos futuros poderiam programar arranjos de modo a verificar se culturantes também obedecem a lei da igualação. Outra possibilidade de investigação, a partir da programação de esquemas concorrentes para culturantes, é a possibilidade de se investigar a resistência à mudança. Esta é uma questão central no planejamento cultural. A Análise Comportamental da Cultura poderá auxiliar a resolução de dificuldades enfrentadas pela humanidade, como práticas não sustentáveis, ao descrever quais fatores aumentam ou diminuem a mudança em práticas culturais, a depender de como tais práticas produziram consequências culturais no passado.

Além disso, este estudo demonstrou a possibilidade de utilização de delineamento intra-sujeito para investigação em metacontingências. Por outro lado, este procedimento precisa ser revisto. Neste estudo não foram manipuladas consequências individuais para cada comportamento operante de cada participante. As consequências operantes foram fornecidas por outros participantes, como por exemplo, elogiar ou agradecer a escolha do participante pelo cartão. A ausência de programação de reforços pode ter contribuído para que outros eventos ambientais possam ter exercido controle na seleção de culturantes. Por exemplo, a mudança de preferência por cartão menos efetivo na geração 8 e 9 do Grupo 2, condição A. Outra dificuldade encontrada referese à caracterização dos culturantes. Neste estudo, os debates entre participantes referentes à escolha dos cartões 
caracterizou as CCEs. Para registro dos culturantes foi utilizada a mensuração do produto agregado (escolha consensual). Essa estratégia de registro apresenta ao menos duas dificuldades. A primeira é em relação à possibilidade de se observar a evolução dos culturantes. Não foram registradas situações nas quais não havia acordo consensual nas escolhas; assim não foi possível verificar se as escolhas consensuais aumentaram de frequência à medida que $\mathrm{CCs}$ eram apresentadas. A segunda dificuldade envolve a demonstração da relação de dependência entre os comportamentos que compunham os culturantes. Como a estratégia de registro dos culturantes envolveu a ocorrência do produto agregado, foi inferido que os comportamentos estavam inter-relacionados. A demonstração empírica da relação de dependência entre os comportamentos é de suma importância para a definição do produto agregado. Em um estudo experimental é esperado que essas relações sejam demonstradas e não apenas inferidas. Em estudos futuros sugere-se que sejam utilizados procedimentos que permitam registrar a relação de dependência entre os comportamentos envolvidos de modo a caracterizar CCEs.

\section{REFERÊNCIAS}

Andery, M. A. P. A. (2011). Comportamento e cultura na perspectiva da análise do comportamento. Perspectivas em Análise do Comportamento, 2, 203-217.

Baia, F. H., Azevedo, F. F., Segantini, S. M., Macedo, R. P., \& Vasconcelos, L. A. (2015). Efeitos de diferentes magnitudes de consequências individuais e culturais sobre culturantes. Acta Comportamentalia, 23(3), 257272.

Baum, W. M., Richerson, P. J., Efferson, C. M., \& Paciotti, B. M. (2004). Cultural evolution in laboratory microsocieties including traditions of rule giving and rule following. Evolution and Human Behavior, 25(5), 305-326. doi:10.1016/j.evolhumbehav.2004.05.003

Boren, J. J. (1966). An experimental social relation between two monkeys. Journal of the Experimental Analysis of Behavior, 9(6), 691-700. doi:10.1901/jeab.1966.9-691

Caldas, R. A. (2009). Análogos experimentais de seleção de extinção de metacontingências. Dissertação de
Mestrado. Pontifícia Universidade Católica de São Paulo. São Paulo.

Cavalcanti, D. E., Leite, F. L., \& Tourinho, E. Z. (2014). Seleção de práticas culturais complexas: avaliação experimental de um análogo do procedimento de aproximação sucessiva. Psicologisa E Saber Social, $3(1), 2-21$.

Glenn, S. S. (1989). Verbal behavior and cultural practices. Behavior Analysis and Social Action, 7, 10 15.

Glenn, S. S. (2004). Individual Behavior, culture, and social change. The Behavior Analyst, 2(2), 133-151.

Glenn, S. S., \& Malott, M. E. (2004). Complexity and selection: Implications for organizational change. Behavior and Social Issues, 13, 89-106.

Hernstein, R. J. (1961). Relative and absolute strength of a response as a function of frequency of reinforcement. Journal of the Experimental Analysis of Behavior, 4, 267-272.

Hunter, C. S. (2012). Analyzing behavioral and cultural selection contingencies. Revista Latinoamericana de Psicologia, 44(1), 43-54.

Ortu, D., Becker, A. M., Woelz, T. A. R., \& Glenn, S. S. (2012). An iterated four-player prisoner's dilemma game with an external selecting agent: A metacontingency experiment. Revista Latinoamericana de Psicologia, 44(1), 111-120.

Sampaio, A. A. S., \& Andery, M. A. P. A. (2010). Comportamento social, produção agregada e prática cultural: uma análise comportamental de fenômenos sociais. Psicologia: Teoria E Pesquisa, 26, 183-192.

Skinner, B. F. (1953). Science and human Behavior. Free Press.

Vichi, C., Glenn, S. S., \& Andery, M. A. P. A. (2009). A metacontingency experiment: Effects of contingent consequences on patterns of interlocking contingencies of reinforcement. Behavior and Social Issues, 18, 4157.

Vichi, C., \& Tourinho, E. Z. (2011). Consequências culturais $\mathrm{X}$ consequências comportamentais na literatura experimental de pequenos grupos. Acta Comportamentalia, 20, 201-215. 